\title{
Methodological Refinement of Upper Limb Kinematics of Spinal Cord Injured Patients Through Principal Component Analyses
}

\author{
De los Reyes Guzmán Ana ${ }^{1, *}$, López Dolado Elisa ${ }^{2}$, Monasterio Huelin Félix ${ }^{3}$ and Gil Agudo Ángel ${ }^{1,2}$ \\ ${ }^{1}$ Biomechanics and Technical Aids Department, National Hospital for Paraplegics (SESCAM), Spain \\ ${ }^{2}$ Rehabilitation Department, National Hospital for Paraplegics (SESCAM), Spain \\ ${ }^{3}$ Escuela Técnica Superior Ingenieros de Telecomunicación, Spain
}

*Corresponding author: De los Reyes Guzmán Ana, Biomechanics and Technical Aids Department, National Hospital for Paraplegics

(SESCAM), Spain

\begin{abstract}
ARTICLE INFO
Received: 幽 November 28, 2019

Published: 亚December 09, 2019

Citation: De los Reyes Guzmán Ana, López Dolado Elisa, Monasterio Huelin Félix, Gil Agudo Ángel. Methodological Refinement of Upper Limb Kinematics of Spinal Cord Injured Patients Through Principal Component Analyses. Biomed J Sci \& Tech Res 23(4)-2019. BJSTR. MS.ID.003942.
\end{abstract}

Keywords: Principal Component Analysis; Kinematic indices; Upper Limb; Rehabilitation; Activities of Daily Living; Spinal Cord Injuries

Abbreviations: SCI: Spinal Cord Injury; PCA: Principal Component Analysis; ASIA: American Spinal Injury Association

\section{ABSTRACT}

Upper limb strength is impaired to some extent in people who have suffered neurological diseases as cervical spinal cord injury (SCI). More than $70 \%$ of these patients had expressed as a very important improvement in the quality of their lives the potential restoration in arm and hand function. In this context, quantitative measures of human movement quality are significant in the rehabilitation field for expressing the outcomes attributable to particular treatments, discriminating between healthy and pathological conditions and/o reporting on the degree of recovery achieved. Three-dimensional kinematics analysis equipments are used for quantifying human movements in clinical laboratories, providing objectivity to the patient assessments. Nowadays, the efficient management of the data sets obtained is a demand and a challenge in the clinical setting. A set of novel kinematic indices, as a combination of kinematic variables, for quantifying upper limb motor disorders have been proposed for measuring patients' motor performance during the activity of daily living of drinking from a glass related to ability and dexterity such as accuracy, efficiency, agility, smoothness and coordination. However, the relationship between the set of kinematic indices hasn't been analyzed in previous studies. We present an application of the PCA statistical method that can account for the relations between the kinematic indices proposed in our previous studies. The analysis has been made in the indices results from healthy people and SCI patients. As conclusion, PCA allows for the detection of different motor control characteristics in both populations analyzed and the influence of the injury in the importance and relevance of the characteristics detected

\section{Introduction}

Upper limb motor control is impaired to some extent in people who have suffered neurological diseases as cervical spinal cord injury (SCI), making it difficult for them to perform autonomously the activities of daily living. More than $70 \%$ of cervical SCI patients had expressed as a very important improvement in the quality of their lives the potential restoration in arm and hand function $[1,2]$. In this context, quantitative measures of human movement quality are significant in the rehabilitation field for expressing the outcomes during different kind of treatments, including rehabilitation, discriminating between healthy and pathological conditions, and for helping in the decision making in the clinical setting $[3,4]$. Three-dimensional kinematic analysis equipment's are used for quantifying human movements in clinical laboratories. These systems may provide objectivity to the patient assessments. Nowadays, the kinematic variables found in the literature have some deficiencies, and the efficient management of these data sets is a demand and a challenge in the clinical setting. In this sense, a set of novel kinematic indices, as a combination of kinematic 
variables, for quantifying upper limb motor disorders have been proposed. These kinematic indices assess the upper limb function in terms of characteristics in relation to ability and dexterity such as accuracy, efficiency, agility, smoothness and coordination. These indices are defined for measuring patients' motor performance during the activity of daily living of drinking from a glass. In this way, the capability of the kinematic indices for discriminating between the healthy and pathological condition after cervical SCI was analyzed $[5,6]$.

Neurological pathologies like SCI, stroke, Parkinson disease and other ones are all know to affect gross motor coordination, obtaining impairment of sensorimotor patterns during the performance of behaviors such as gait and UL activities related to objects manipulation [7]. Only modest advances have been made in identifying and quantifying the observed differences between healthy and pathological condition. So, Daffertshofer et al. maintained that the application of Principal Component Analysis (PCA) method may help to strengthen these comparisons. To apply PCA within the rehabilitation and other interventions fields may help to detect changes in the coordination patterns and motor control features. However, the relationship between the set of kinematic indices hasn't been analyzed in previous studies. Principal components analysis (PCA) or factor analysis has been previously applied for studying the grasping movement $[8,9]$ the control of hand prostheses [10] and gestures recognition [11,12]. Moreover, this statistical method has not been very much used within the field of UL movement coordination and motor control, even though it has proven valid to reduce data dimensionality and redundant information in a data structure. The aim of the present work is to apply the PCA statistical method that can account for the relations between the kinematic indices proposed in our previous studies. To carry it out, the indices results from a sample of healthy subjects and two different groups of cervical spinal cord injured patients were used.

\section{Materials and Methods}

\section{Participants}

The sample analyzed and included in the study was of 21 subjects, divided into three different groups: a healthy subjects (HS) group (n=7); plus two more groups of patients with motor complete cervical SCI with metameric level C6 ( $n=7)$ and C7 (n=7) respectively. Although $\mathrm{C} 6 \mathrm{SCI}$ patients are more affected that $\mathrm{C} 7$ SCI patients, all of them retain control of the elbow flexors and the wrist extensor muscles but only $\mathrm{C} 7$ patients retain strong active control of the elbow extensor muscle in addition to elbow flexors and wrist extensors. However, both patients' groups lose the ability to perform active prehension movements [13]. The inclusion criteria were the following: age between 16 and 65 years, injury of at least 6 months' duration and level of cervical injury, metameric levels C6 or C7, neurologically classified according to the American Spinal Injury Association (ASIA) scale into grades A or B [14]. So, all the patients suffered a cervical SCI complete in the motor aspect. Patients who presented any exclusion criteria as vertebral deformity, UL joint constraint, balance disorders or cognitive deficit were excluded. Patients were classified into C6 and C7 SCI by a physical examination performed by a physiatrist-board certified in SCI medicine.

The ASIA right upper limb motor index (ULR) was obtained [14], with the assessment of the strength of five muscles groups of the right UL. Each muscle group can be assessed between the score 0 (no function) to 5 (normal function) with a total of 25 points. The guidelines of the declaration of Helsinki were followed in every case. Informed consent was obtained from all individual participants included in the study, which was approved by the Local Ethics Committee, Toledo, Spain. For the statistical analyses of these variables, one-way ANOVA, unpaired Student's t test and Chi square test $(\chi 2)$ were performed with Sigma Plot 17.0 software. All results were considered statistically significant at $\mathrm{p}<0.05$.

\section{Experimental Setup}

UL movement was recorded by means of the Coda motion photogrammetry system (Charnwood Dynamics, Ltd, UK) based on active markers, which connected to the batteries emit infrared light captured by three scanner units. For the performance of this study 21 markers were used, placed on the skin surface in the trunk and the right arm (Figure 1): 8 markers allowed to compose the biomechanical UL model, consisted on the trunk, arm, forearm and hand body segments; the other 13 markers were located on clusters to determine the position and orientation of each body segment in the space. So, three markers clusters were used: one on the trunk, other one on the arm and the last one on the forearm. However, the corresponding three markers of the hand were placed on the dorsal side on the skin surface. 3D marker positions are calculated instantly with a spatial resolution of 0.1 $\mathrm{mm}$. All the participants, instrumented with Coda motion markers and seated in a wheelchair in front of a table, adjustable in height, performed only one experimental session in the laboratory. The proof consisted on the execution of 5 complete cycles of the ADL of drinking. All this experimental setup was described in detail in a previous study [15].

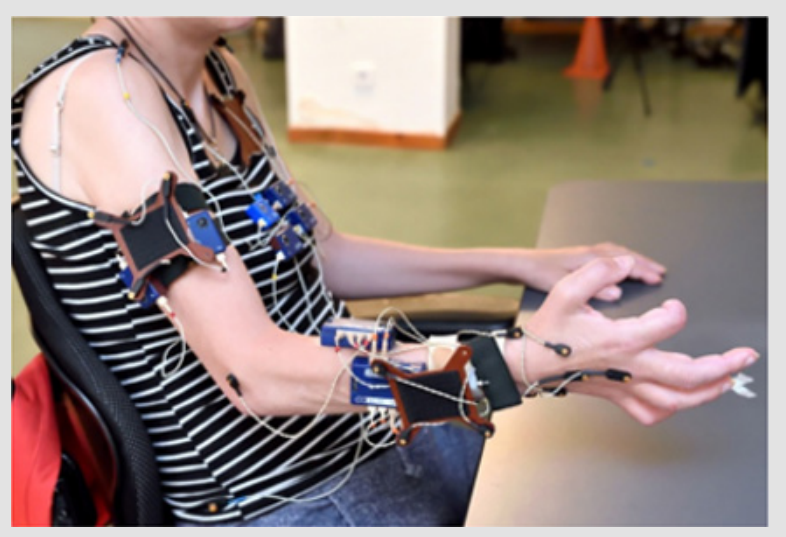

Figure 1: A patient instrumented with Coda motion markers during an experimental session. 
We introduced two changes with respect to the previous experimental protocol we had used in previous works: the first one was the distance to the glass placed on the table -in this study the glass was placed in the midline of the body, to the $75 \%$ of the maximal UL reaching [16] with the aim of avoiding the performance of compensatory movements of the trunk- and the second one was the inclusion of an additional scanner unit with the aim of improving the data acquisition and markers visibility. The drinking ADL included to reach and grasp the glass, to lift the glass to the mouth, to simulate a swallow, releasing the glass on the table and returning to the starting position. They were instructed for initiating the drinking task at a self-selected speed. All the participants were right-handed and performed the movement with their right arms. For computing joint kinematics from position data of Coda motion markers, a biomechanical model of 6 degrees of freedom (DoF) previously published was used [15]. Data were filtered with second-order Butterworth filter with a cut-off frequency of $4 \mathrm{~Hz}$. The model included the trunk, right arm, right forearm and the right-hand body segments. The rotation centers were estimated from markers placed on bony prominences on the skin surface. Kinematic indices in relation to dexterity and ability of the UL were calculated from hand trajectory during a complete cycle of the drinking ADL and the speed profile in magnitude, obtaining by the computing of the first derivative.

To facilitate analysis, the drinking ADL was divided into 5 consecutive phases, following Murphy's study guidelines [17].

\section{Kinematic Indices}

Kinematic indices assess UL ability and dexterity, such as accuracy, agility, efficiency, smoothness and coordination. UL functional deficits after neurological diseases are reflected in compensatory movements in proximal joints. Hence, these indices were designed and validated to detect UL functional. The complete development of the kinematic indices was described in detail, including their capability to discriminate between the healthy and pathological condition after a cervical SCI $[5,6]$.

\section{Principal Component Analysis}

PCA is applied to extract the relevant information within high dimensional data samples by considering only those principal components that explain sufficiently high fractions of the complete data set in function of its variance [7]. But when PCA is chosen to analyze a data sample, part of the correct procedure involves checking that the dataset to analyze can be analyzed by using this statistical method. So, several assumptions in relation to the dataset have to be considered [18]. To apply the Principal Component Analysis statistical method, SPSS software was used.

\section{Results}

\section{Demografics}

No statistically significant differences were found between the three subpopulations studied related to gender $(\chi 2, p>0,05)$, age in

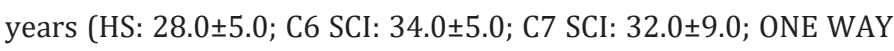
ANOVA, $p>0,05$ ) and anthropometric parameters- height in $\mathrm{cm}$ (HS: $168 \pm 20.0$; C6 SCI: $175.0 \pm 10.0$; C7 SCI: 182.0 \pm 8.0 ; ONE WAY ANOVA, p>0,05); weight in Kg (HS: 65 \pm 21.1 ; C6 SCI: 90.2 \pm 7.1 ; C7 SCI: 82.5 \pm 9.1 ; ONE WAY ANOVA, $p>0,05$ ).

Background data of participants are provided in Table 1.

Table 1: Demographic characteristics of the sample analyzed.

\begin{tabular}{|c|c|c|c|c|c|c|c|}
\hline & \multicolumn{2}{|c|}{ Demografic Variables } & \multicolumn{2}{|c|}{ Anthopometric Variables } & \multicolumn{3}{|c|}{ SCI Derived Variables } \\
\hline & Gender (\%male) & Age (years)* & Height $(\mathrm{cm})^{*}$ & Weight* (kg) & Time after SCI (months)* & AIS(\%A /\%B) & ULR \\
\hline $\begin{array}{l}\text { Healthy Subjets } \\
\text { (HS) }\end{array}$ & $3(42.8)$ & $28.0(5.0)$ & $168.0(20.0)$ & $65.0(21.1)$ & - & - & $25.0(0.0)$ \\
\hline C6 SCI patients & $4(57.4)$ & $34.0(5.0)$ & $175.0(10.0)$ & $90.2(7.1)$ & $8.5(2.2)$ & $\begin{array}{l}3(42.8) \\
/ 4(57.2)\end{array}$ & $13.0(3.0)$ \\
\hline C7 SCI patients & $4(57.4)$ & $32.0(9.0)$ & $182.0(8.0)$ & $82.5(9.1)$ & $7.5(1.8)$ & $\begin{array}{c}3(42.8) / 4 \\
(57.2)\end{array}$ & $17.6(4.4)$ \\
\hline
\end{tabular}

\section{Principal Component Analysis}

The components extracted from the application of PCA method are shown in Table 2. The accumulated percentage of explained variance from the data sample related to the kinematic indices was for the HS $94.826 \%$ by means of four principal components versus $81.755 \%$ for the SCI patients' group taken C6 and C7 SCI subjects together by means of only three components. From the loading matrix, the HS four components were related to accuracy (including efficiency), agility, coordination and smoothness (Table 3). However, the SCI patients' accumulated variance was distributed as follows: the first was related to accuracy, the second, to a combination of agility, coordination and smoothness; and the third, to efficiency. To determine if the procedure we propose was able to discriminate between patients with different metameric levels of spinal injury, a second analysis was carried out, separating the patients between C6-SCI and C7-SCI. Interestingly, the accumulated percentage of explained variance was for the C6SCI patients $94.361 \%$ by means of three principal components but amounted to $100 \%$ for the C7-SCI patients and by means of only two ones (Table 2). From the loading matrix, the C6-SCI patients' accumulated variance remained distributed related to firstly to accuracy and efficiency, secondly to the same combination of agility, coordination and smoothness and thirdly to smoothness (Table 4). 
However, the first component of the accumulated variance among efficiency and smoothness and the second and the last, to another the C7-SCI patients' was related to a combination of accuracy, combination of agility, coordination and smoothness (Table 5).

Table 2: Eigenvalues and percentages of variance associated with each component for the three groups analyzed.

\begin{tabular}{|c|c|c|c|c|c|c|c|c|c|}
\hline & \multicolumn{3}{|c|}{ Healthy subjects } & \multicolumn{3}{c|}{ C7 SCI } & \multicolumn{3}{c|}{ C6 SCI } \\
\hline COMPONENT & Eigenvalue & \% var & \%accum & Eigenvalue & \% var & \%accum & Eigenvalue & \% var & \%accum \\
\hline 1 & 5.866 & 48.887 & 48.887 & 6.594 & 54.951 & 54.951 & 6.100 & 50.834 & 50.834 \\
\hline 2 & 2.569 & 21.406 & 70.293 & 5.406 & 45.049 & 100.000 & 3.490 & 29.080 & 79.915 \\
\hline 3 & 1.555 & 12.959 & 83.252 & & & & 1.734 & 140446 & 94.361 \\
\hline 4 & 1.389 & 11.573 & 94.826 & & & & & & \\
\hline
\end{tabular}

Note: \% var corresponds to the percentage of explained variance and \% accum corresponds to the accumulated percentage of explained variance.

Table 3: Loading matrix of component solution performed on the kinematic indices computed for the HEALTHY SUBJECTS. Salient loading values are printed in bold font.

\begin{tabular}{|c|c|c|c|c|}
\hline \multicolumn{5}{|c|}{ Components } \\
\hline Index & $\mathbf{1}$ & $\mathbf{2}$ & $\mathbf{3}$ & $\mathbf{4}$ \\
\hline Accuracy $(\mathrm{A})$ & $\mathbf{0 . 9 5}$ & 0.14 & -0.06 & 0.28 \\
\hline$\alpha$ & $\mathbf{0 . 9 8}$ & -0.08 & -0.10 & -0.02 \\
\hline$\rho$ & $\mathbf{0 . 9 6}$ & -0.20 & 0.11 & -0.08 \\
\hline BN & $\mathbf{0 . 8 3}$ & 0.29 & -0.14 & 0.42 \\
\hline Agility $\left(\mathrm{A}_{\mathrm{g}}\right)$ & $\mathbf{0 . 8 9}$ & -0.39 & 0.06 & 0.17 \\
\hline$\mu$ & 0.28 & $\mathbf{- 0 . 9 1}$ & 0.27 & -0.09 \\
\hline$\gamma$ & -0.27 & $\mathbf{0 . 6 4}$ & -0.50 & 0.10 \\
\hline Efficiency $(\mathrm{E})$ & -0.78 & -0.54 & 0.11 & 0.27 \\
\hline Coordination $(\mathrm{C})$ & 0.08 & 0.09 & $\mathbf{0 . 6 1}$ & -0.35 \\
\hline Smoothness $\left(\mathrm{S}_{1}\right)$ & 0.09 & 0.09 & 0.41 & $\mathbf{0 . 8 3}$ \\
\hline Smoothness $\left(\mathrm{S}_{2}\right)$ & $\mathbf{0 . 8 1}$ & 0.17 & 0.54 & -0.02 \\
\hline
\end{tabular}

Table 4: Loading matrix of component solution performed on the kinematic indices for the C6 SCI PATIENTS'GROUP. Salient loading values are printed in bold.

\begin{tabular}{|c|c|c|c|}
\hline \multicolumn{5}{|c|}{ Components } \\
\hline Index & $\mathbf{1}$ & $\mathbf{2}$ & $\mathbf{3}$ \\
\hline Accuracy $(\mathrm{A})$ & $\mathbf{0 . 9 3}$ & -0.22 & 0.27 \\
\hline$\alpha$ & $\mathbf{0 . 9 2}$ & -0.22 & 0.03 \\
\hline$\rho$ & $\mathbf{0 . 9 4}$ & -0.20 & 0.12 \\
\hline BN & $\mathbf{0 . 8 7}$ & -0.31 & 0.34 \\
\hline Agility $\left(\mathrm{A}_{\mathrm{g}}\right)$ & $\mathbf{0 . 9 1}$ & -0.18 & 0.33 \\
\hline$\mu$ & -0.35 & $\mathbf{- 0 . 6 7}$ & 0.50 \\
\hline$\gamma$ & 0.28 & $\mathbf{0 . 9 0}$ & 0.17 \\
\hline Efficiency $(\mathrm{E})$ & $\mathbf{- 0 . 6 5}$ & 0.49 & 0.53 \\
\hline Coordination $(\mathrm{C})$ & 0.52 & 0.72 & 0.41 \\
\hline Smoothness $\left(\mathrm{S}_{1}\right)$ & 0.43 & 0.83 & -0.15 \\
\hline Smoothness $\left(\mathrm{S}_{2}\right)$ & $\mathbf{- 0 . 5 8}$ & 0.38 & $\mathbf{0 . 6 7}$ \\
\hline
\end{tabular}

Table 5: Loading matrix of component solution performed on the kinematic indices for the C7 SCI group. Salient loading values are printed in bold.

\begin{tabular}{|c|c|c|}
\hline & \multicolumn{2}{|c|}{ Components } \\
\hline Index & $\mathbf{1}$ & $\mathbf{2}$ \\
\hline Accuracy $(\mathrm{A})$ & $\mathbf{0 . 9 8}$ & -0.16 \\
\hline$\alpha$ & $\mathbf{0 . 9 5}$ & 0.28 \\
\hline$\rho$ & $\mathbf{0 . 8 4}$ & -0.53 \\
\hline BN & $\mathbf{0 . 9 9}$ & 0.08 \\
\hline Agility $\left(\mathrm{A}_{\mathrm{g}}\right)$ & $\mathbf{0 . 8 2}$ & 0.46 \\
\hline$\mu$ & 0.38 & $\mathbf{0 . 9 2}$ \\
\hline$\gamma$ & -0.02 & $\mathbf{1 . 0 0}$ \\
\hline Efficiency $(\mathrm{E})$ & $\mathbf{- 0 . 9 5}$ & 0.30 \\
\hline Coordination $(\mathrm{C})$ & 0.15 & $\mathbf{0 . 9 8}$ \\
\hline Smoothness $\left(\mathrm{S}_{1}\right)$ & 0.17 & $\mathbf{0 . 9 8}$ \\
\hline Smoothness $\left(\mathrm{S}_{2}\right)$ & $\mathbf{0 . 9 3}$ & -0.36 \\
\hline
\end{tabular}

\section{Discussion}

In this study we present an application of the PCA statistical method that can account for the relations between the kinematic indices proposed in our previous studies. It was decided to carry out a deeper statistical analysis of our previous kinematic data to test the ability of the PCA procedure to discriminate between different SCI patient populations, with different metameric level of injury and subsequently different upper limbs motor control. As far as the authors' knowledge goes, this is the first work that applies the PCA to a sample of spinal cord injured patients with severe and complex deficits in the upper limbs motor behavior. We found that, for the ADL of drinking, the PCA of our previously described kinematic indices was able to detect different motor control characteristics between healthy subjects and patients with cervical SCI but also between patients with two different metameric levels of injury, C6 and C7 motor complete ASIA A or B. We decided not to include motor incomplete lesions ASIA grade $\mathrm{C}$ and $\mathrm{D}$ in this first study, since the heterogeneity in motor behavior among them is greater and more complex to understand. It has been extensively proven the ability of kinematic analyses to accurately describe the characteristics of the upper limbs motor control after cervical SCI, 
either the main deficits or the secondary behavioral compensations $[19,20]$, compared to the clinical scales commonly used $[5,6]$ On the other hand, it is also well established that the factor that most directly determines residual motor behavior after SCI is the metameric level [21].

Although our data have proven useful to differentiate between C6 and C7 motor complete SCI patients and between healthy and spinal injured subjects, it is worth mentioning that these three subpopulations shared many of the indices in the first principal component, which could mean that the motor control characteristics that these indices represent- accuracy and efficiency especiallywould be predominantly selected in all types of motor behavior, both normal and pathological. PCA analysis was previously applied to study the grasping movement $[8,9]$ the control of hand prostheses [10] and gestures recognition [11,12]. In relation to UL kinematics, Merlo et al. investigated by means of this method, the dependency on the task characteristics of several kinematic variables measured form Armeo Spring device in healthy subjects [22]. In future works it will be necessary to confirm our results with a larger sample that also includes incomplete motor patients and the analysis of the distribution of each of them according to the main component in which they are found, in order to determine if they exist really patterns associated with each level and what is its physiological significance.

\section{Conclusion}

As conclusion, PCA allows for the detection of different motor control characteristics in both populations analyzed and the influence of the injury in the importance and relevance of the characteristics detected. These motor control characteristics will be computed by the Leap Motion Controller device.

\section{Acknowledgement}

This research has been funded by grant from the Spanish Ministry of Economy and Competitivity and cofunded from FEDER, National Plan for Scientific and Technological Research and Innovation. Project RehabHand (Plataforma de bajo coste para rehabilitación del miembro superior basado en Realidad Virtual, ref. DPI2016-77167-R) and from MINECO and the Fondo Europeo de Desarrollo Regional (MAT2016-78857-R, AEI/FEDER, UE).

\section{References}

1. Mekki M, Delgado AD, Fry A, Putrino D, Huang V (2018) Robotic rehabilitation and spinal cord injury: a narrative review. Neurotherapeutics 15(3): 604-617.

2. Quel de Oliveira C, Refshauge K, Middleton J, De Jong L, Davis GM (2017) Effects of activity-based therapy interventions on mobility, independence and quality of life for people with spinal cord injuries: a systematic review and meta-analysis. Journal of neurotrauma 34(9): 1726-1743.

3. Ditunno JF (2010) Outcome measures: evolution in clinical trials of neurological/functional recovery in spinal cord injury. Spinal Cord 48(9): 674

4. Carrasco López C, Jimenez S, Mosqueda Pozon MC, Pérez Borrego YA, Alcobendas Maestro M (2016) New insights from clinical assessment of upper extremities in cervical traumatic spinal cord injury. Journal of neurotrauma 33(18): 1724-1727.

5. De los Reyes Guzman A, Dimbwadyo Terrer I, Pérez NombelaS, Monasterio Huelin F, Torricelli D (2016) Novel kinematic indices for quantifying movement agility and smoothness after cervical Spinal Cord Injury. NeuroRehabilitation 38(2): 199-209.

6. De los Reyes Guzmán A, Dimbwadyo Terrer I, Pérez Nombela S, Monasterio Huelin F, Torricelli D (2017) Novel kinematic indices for quantifying upper limb ability and dexterity after cervical spinal cord injury. Medical \& biological engineering \& computing 55(5): 833-844.

7. Daffertshofer A, Lamoth CJ, Meijer OG, Beek PJ (2004) PCA in studying coordination and variability: a tutorial. Clinical biomechanics 19(4): 415-428.

8. Santello M, Flanders M, Soechting JF (1998) Postural hand synergies for tool use. Journal of Neuroscience 18(23):10105-10115.

9. Thakur PH, Bastian AJ, Hsiao SS (2008) Multidigit movement synergies of the human hand in an unconstrained haptic exploration task. Journal of Neuroscience 28(6): 1271-1281.

10. Matrone GC, Cipriani C, Secco EL, Magenes G, Carrozza MC (2010) Principal components analysis-based control of a multi-dof underactuated prosthetic hand. Journal of neuroengineering and rehabilitation $7(1)$ : 16 .

11. Cobos S, Ferre M, Ángel Sánchez Urán, M, Ortego J (2010) Human hand descriptions and gesture recognition for object manipulation. Computer methods in biomechanics and biomedical engineering 13(3): 305-317.

12. Jarque Bou NJ, Scano A, Atzori M, Müller H (2019) Kinematic synergies of hand grasps: a comprehensive study on a large publicly available dataset. Journal of neuroengineering and rehabilitation 16(1): 63.

13. Mateo S, Revol P, Fourtassi M, Rossetti Y, Collet C (2013) Kinematic characteristics of tenodesis grasp in C6 quadriplegia. Spinal cord 51(2): 144.

14. Kirshblum SC, Burns SP, Biering Sorensen F, Donovan W, Graves DE (2011) International standards for neurological classification of spinal cord injury (revised 2011). The journal of spinal cord medicine 34(6): 535-546.

15. De los Reyes Guzmán A, Gil Agudo A, Peñasco Martín B, Solís Mozos M, Del Ama Espinosa A (2010) Kinematic analysis of the daily activity of drinking from a glass in a population with cervical spinal cord injury. Journal of neuroengineering and rehabilitation 7(1): 41.

16. Butler EE, Ladd AL, LaMont LE, Rose J (2010) Temporal-spatial parameters of the upper limb during a reach \& grasp cycle for children. Gait posture 32(3): 301-306.

17. Murphy MA, Sunnerhagen KS, Johnels B, Willén C (2006) Threedimensional kinematic motion analysis of a daily activity drinking from a glass: a pilot study. Journal of neuroengineering and rehabilitation $3(1): 18$.

18. Statistics L (2015) Principal components analysis (PCA) using SPSS Statistics. Statistical tutorials and software guides.

19. Mateo S, Roby Brami A, Reilly KT, Rossetti Y, Collet C (2015) Upper limb kinematics after cervical spinal cord injury: a review. Journal of neuroengineering and rehabilitation 12(1): 9.

20. Murgia A, Kyberd P, Barnhill T (2010) The use of kinematic and parametric information to highlight lack of movement and compensation in the upper extremities during activities of daily living. Gait \& posture 31(3): 300-306.

21. Peljovic AL, Bryden AM, Bohn A, Keith MW (2011) Surgical restoration of the hand in tetraplegia. In: Kirchblum S, Campagnolo DI (Eds.), ( $2^{\text {nd }}$ edn). Philadelphia: Wolters Kluwer/Lippincott Williams and Wilkins. USA Pp: 514.

22. Merlo A, Longhi M, Giannotti E, Prati P, Giacobbi M (2013) Upper limb evaluation with robotic exoskeleton. Normative values for indices of accuracy, speed and smoothness. NeuroRehabilitation 33(4): 523-530. 


\section{ISSN: 2574-1241}

DOI: 10.26717/BJSTR.2019.23.003942

De los Reyes Guzmán Ana. Biomed J Sci \& Tech Res

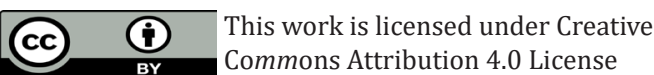

Submission Link: https://biomedres.us/submit-manuscript.php

$\begin{array}{ll}\text { BIOMEDICAL } & \text { Assets of Publishing with us } \\ \text { RESEARCHES } & \text { - Global archiving of articles } \\ \text { - Immediate, unrestricted online access } \\ \text { - Rigorous Peer Review Process }\end{array}$

